Syntax Literate : Jurnal Ilmiah Indonesia p-ISSN: 2541-0849

e-ISSN : 2548-1398

Vol. 4, No. 9 September 2019

\title{
PENGARUH BUDAYA ORGANISASI， KEPEMIMPINAN，LINGKUNGAN KERJA DAN MOTIVASI SEBAGAI VARIABEL INTERVENING TERHADAP KINERJA DOSEN POLITEKNIK DI KOTA BEKASI
}

\section{Diapari Sosagaon Putra Pane}

Program Studi Magister Manajemen Sumber Daya Manusia

Fakultas Ekonomi Universitas Satya Negara Indonesia

Email: putra.pane@yahoo.com

\begin{abstract}
Abstrak
Penelitian ini bertujuan untuk mengetahui pengaruh budaya organisasi, kepemimpinan, lingkungan kerja dan motivasi sebagai variabel intervening terhadap kinerja dosen politeknik di kota bekasi. Penelitian ini menganalisis data dari sampel sebanyak 99 dosen yang diambil dengan menggunakan metode stratifikasi random sampling dari populasi sebanyak 132. Dosen tersebut adalah dosen yang mengajar pada Politeknik di Kota Bekasi. Pengambilan data dilakukan mulai dari Januari-Maret 2019. Analisis data menggunakan model SEM dengan menggunakan program AMOS versi 22,0. Hasil penelitian ini menunjukkan Budaya Organisasi berpengaruh positif terhadap motivasi, kepemimpinan berpengaruh positif terhadap motivasi, Lingkungan kerja berpengaruh positif terhadap motivasi, motivasi berpengaruh positif terhadap kinerja dosen, budaya organisasi berpengaruh positif terhadap kinerja dosen, Kepemimpinan berpengaruh positif terhadap kinerja dosen, lingkungan kerja berpengaruh positif terhadap kinerja dosen, Budaya organisasi berpengaruh terhadap kinerja dosen melalui motivasi, kepemimpinan berpengaruh terhadap kinerja dosen melalui motivasi dan lingkungan kerja berpengaruh terhadap kinerja dosen melalui motivasi.
\end{abstract}

Kata Kunci: Budaya Organisasi, Kepemimpinan, Lingkungan Kerja, Motivasi, Kinerja Dosen

\section{Pendahuluan}

Manajemen sumber daya manusia merupakan pilar yang memiliki tuntutan utama bagi organisasi, dalam mendukung pola penentuan strategi dan kebijakan secara terpadu. Keputusan sumber daya manusia yang baik perlu didukung oleh kualitas pelaksanaan menajemen sumber daya manusia. Sumber daya manusia merupakan bagian penting dalam aktivitas kerja. Karena hal tersebut berhubungan dengan masalah kualitas kerja dan pencapaian kerja (Saridawati, 2018). Sumber daya dosen merupakan sesuatu yang sangat berharga bagi suatu perguruan tinggi. Untuk mewujudkan tujuan 


\section{Diapari Sosagaon Putra Pane}

diatas perlu peningkatan sumber daya dosen yang bermutu. Peningkatan tersebut antara lain perlu seorang pemimpin yang mampu mengelola sumber daya yang ada dengan baik dan tenaga pendidik atau dosen yang profesioanal serta lingkungan kerja yang baik dan kondusif demi mendukung kinerja dosen yang dapat meningkatkan prestasi mahasiswanya meningkat.

Tuntutan terhadap peningkatan kinerja dosen di Politeknik di Kota Bekasi menunjukkan sebagai tuntutan yang nyata. Hal ini mengingat adanya beberapa indikasi perlunya peningkatan kualitas disegala bidang. Kinerja dosen dapat dikaji dari penilaian kinerja kerja, karena penilaian kinerja dosen merupakan proses dimana perguruan tinggi mengevaluasi prestasi kerja dosen. Penilaian terhadap kinerja dosen perlu dilakukan, karena dengan penilain kinerja dosen akan dapat diketahui faktor-faktor yang mempengaruhi penurunan atau peningkatan kinerja dosen.

(Suddin, 2010) memberikan bukti bahwa kepemimpinan, motivasi dan lingkungan kerja memiliki pengaruh yang signifikan. Temuan dalam penelitian ini juga menunjukkan bahwa tinggi rendahnya kinerja pegawai dipengruhi oleh kepemimpinan, motivasi, dan lingkungan kerja. Artinya apabila kepemimipinan, motivasi dan lingkungan kerja semakin baik maka kinerja yang dihasilkan oleh pegawai juga semakin baik. (Rahmayanti \& Afandi, 2014) menunjukkan bahwa kepemimpinan, motivasi, dan lingkungan kerja memberikan pengaruh positif terhadap kinerja karyawan.

Salah satu hal yang perlu mendapat perhatian berhubungan dengan kinerja karyawan adalah kinerja dosen pada perguruan tinggi politeknik di Kota Bekasi. Kinerja karyawan dapat diukur dari aspek seperti kualitas bekerja, jumlah pekerjaan yang diselesaikan, pengetahuan jabatan dan kreativitas (Gomes dalam Eko Numiarto (1985) dan Nurhadi S (2006). Permasalahan kinerja tersebut dilihat dari kualitas bekerja adalah masih banyak dosen pada politeknik tersebut yang menghasilkan lulusan kurang seperti yang diharapkan dilihat dari pencapaian indeks prestasi kumulatif, lama waktu penyelesaian kuliah dan diterima bekerja pada suatu perusahaan atau melakukan kewirausahaan. Selain itu belum terciptanya iklim akademik yang terbuka dan adil, tingkat kehadiran dosen yang rendah, dan belum adanya kesamaan persepsi tentang standar kerja yang merupakan parameter yang menandakan etos kerja di lingkungan staf akademik masih rendah. Tingkat kehadiran dosen yang rendah, hasil penelitian dan karya tulis staf akademik belum terpublikasikan secara maksimal karena belum adanya 
Pengaruh Budaya Organisasi, Kepemimpinan, Lingkungan Kerja dan Motivasi Sebagai

Variabel Intervening Terhadap Kinerja Dosen

sistem informasi manajemen (SIM) staf akademik yang terpadu serta dapat diakses oleh seluruh sivitas akademik di lingkungan internal dan eksternal kampus Politeknik di Kota Bekasi.

Faktor budaya organisasia dapat dilihat dari kedisiplinan dosen dalam mengajar. Salah satu permasalahan yang muncul pada salah satu politeknik adalah pada tahun 2018 tingkat kesadaran kedisiplinan dosen rendah (rata-rata per bulan) yaitu mangkir sebanyak 10 orang, tidak tepat waktu dalam mengajar 11 orang, sakit 3 orang dan ijin 2 orang dimana sebagian besar dosen belum memiliki jabatan fungsional (Pudir 1, 2018). Dampak dari ketidak kedisiplinan tersebut mengganggu efesiensi kerja dan efektifitas tugas dosen dalam melaksanakan tridarma perguruan tinggi yaitu pendidikan dan pengajaran, penelitian dan pengembangan dan pengabdian kepada masyarakat. Hal tersebut menggambarkan tingkat kinerja dosen rendah.

Dari uraian latar belakang diatas peneliti tertarik untuk meneliti lebih mendalam tentang bagaimana pengaruh budaya organisasi, kepemimpinan, lingkungan kerja dan motivasi sebagai variabel intervening terhadap kinerja dosen politeknik di kota Bekasi.

\section{Metode Penelitian}

\section{Desain Penelitian}

Penelitian ini menggunakan desain penelitian eksplanatif dan kuantitatif serta dilakukanpenelaahan hubungan antar variabel (desain kausal) dengan menggunakan variabel intervening yang berguna untuk mengukur antar variabel, menganalisis bagaimana pengaruh suatu variabel terhadap variabel lainnya. Menurut (Priyono, 2016), penelitian eksplanatif dilakukan untuk menemukan penjelasan tentang mengapa suatu kejadian atau gejala terjadi dan hasil akhir dari penelitian adalah gambaran mengenai hubungan sebab akibat Metode penelitian yang digunakan adalah metode survey, dengan alat bantu berupa kuesioner, dimana responden memilih salah satu jawaban yang telah disediakan, dengan menggunakan skala likert, dengan variasi skor : (5) sangat setuju (1) sangat tidak setuju. Menurut (Priyono, 2016) penelitian survey merupakan penelitian yang menggunakan kuesioner sebagai instrument penelitian. 


\section{Sumber Data, Subyek, Objek Penelitian}

\section{a. Sumber Data}

Sumber data yang dipakai terdapat dua jenis data dalam penelitian yaitu data primer dan data sekunder yang berasal dari Kampus Politeknik yang ada di Kota Bekasi.

- Data Primer adalah data yang berasal dari sumber aslinya dan diperoleh secara langsung dari obyek yang diteliti yaitu dosen dan karyawan Kampus Politeknik di Kota Bekasi. Data primer dalam penelitian ini diperoleh melalui daftar pertanyaaan berupa kuesioner yang terdiri dari pertanyaan tentang identitas responden dan tentang empat variabel penelitian.

- Data Sekunder yaitu data yang diperoleh secara tidak langsung dari sumbernya. Data sekunder diperoleh melalui data-data yang telah didokumentasikan yang diperoleh dari Kampus Politeknik di Kota Bekasi.

\section{b. Populasi dan Sampel}

Populasi adalah keseluruhan gejala / satuan yang ingin diteliti yang terdapat 3 kriteria yang harus terpenuhi, yaitu : isi, cakupan dan waktu (Priyono, 2016:102). Populasi dalam penelitian ini adalah dosen pada Kampus Politeknik di kota Bekasi. Teknik penarikan sampel yang digunakan adalah teknik random sampling. Pada penarikan sampel ini diambil secara acak sejumlah sampel dari 132 dosen. Pengambilan sampel menggunakan rumus Slovin yaitu $=132 /\left(1+0,05^{2} \mathrm{X} 132\right)=99$ orang (Sugiyono, 2016). Sampel tersebut kemudian diambil dengan menggunakan metode stratifikasi random sampling dengan jumlah berikut. Pengambilan sampel masing-masing politeknik menggunakan metode strafitikasi.

\section{c. Obyek Penelitian}

Objek penelitian merupakan sesuatu yang menjadi fokus perhatian dalam suatu penelitian.Objek penelitian menjadi sasaran dalam penelitian untuk mendapatkan jawaban dari permasalahan yang terjadi. pada dosen di Kampus Politeknik Kota Bekasi. 
Pengaruh Budaya Organisasi, Kepemimpinan, Lingkungan Kerja dan Motivasi Sebagai Variabel Intervening Terhadap Kinerja Dosen

\section{Hasil Penelitian dan Pembahasan}

\section{A. Hasil Penelitian}

\section{1) Responden}

Penelitian ini dilakukan pada Kampus Politeknik di Kota Bekasi. Dosen pada perguruan tinggi politeknik di Kota Bekasi. Bekasi memiliki sejumlah politeknik khususnya yang dikelola oleh yayasan. Pada penarikan sampel ini diambil secara acak sejumlah sampel dari 132 dosen. Pengambilan sampel menggunakan rumus Slovin yaitu $=132 /\left(1+0,05^{2} \mathrm{X} 132\right)=99$ orang (Sugiyono, 2016).

\section{2) Analisis Validitas}

Tabel 1.

Hasil analisis validitas

\begin{tabular}{|c|c|c|c|c|c|c|c|}
\hline & & & Estimate & S.E. & C.R. & $\mathrm{P}$ & Label \\
\hline MOT & $<--$ & BUD &,- 185 & ,079 & $-2,337$ & ,019 & par_16 \\
\hline MOT & $<--$ & PEM &,- 008 & ,004 & $-1,951$ & ,051 & par_17 \\
\hline MOT & $<--$ & LING & ,680 & ,097 & 6,985 & $* * *$ & par_18 \\
\hline KIN & $<--$ & MOT & $\underline{1,481}$ &, 178 & 8,308 & $* * *$ & par_19 \\
\hline KIN & $<--$ & LING & ,094 & ,048 & 1,974 & ,048 & par_21 \\
\hline KIN & $<--$ & PEM & ,033 & ,008 & 4,225 & $* * *$ & par_22 \\
\hline KIN & $<--$ & BUD &,- 072 & ,078 &,- 924 & ,045 & par_23 \\
\hline MISI & $<--$ & BUD & 1,000 & & & & \\
\hline KON & $<--$ & BUD & 2,033 &, 375 & 5,415 & $* * *$ & par_1 \\
\hline ADAP & $<--$ & BUD & ,051 & , 192 & ,265 &, 041 & par_2 \\
\hline PELIB & $<--$ & BUD & 2,330 & ,474 & 4,917 & $* * *$ & par_3 \\
\hline KEPRIB & $<--$ & PEM & 1,000 & & & & \\
\hline TEMP & $<--$ & PEM & ,176 &, 025 & 7,054 & $* * *$ & par_4 \\
\hline KEB & $<--$ & PEM & , 100 & ,018 & 5,498 & $* * *$ & par_5 \\
\hline SIFAT & $<--$ & PEM & , 158 &, 025 & 6,271 & $* * *$ & par_6 \\
\hline HUB & $<--$ & LING & 1,000 & & & & \\
\hline KEAM & $<--$ & LING & ,628 & ,065 & 9,701 & $* * *$ & par_7 \\
\hline RUANG & $<--$ & LING &, 118 & ,087 & 1,364 & ,033 & par_8 \\
\hline PENER & $<--$ & LING &,- 026 & ,082 &,- 322 & ,047 & par_9 \\
\hline FISIOLOGIS & $<--$ & MOT & 1,000 & & & & \\
\hline KEAMANAN & $<--$ & MOT & 1,122 &, 127 & 8,855 & $* * *$ & par_10 \\
\hline SOSIAL & $<--$ & MOT & 1,213 & ,133 & 9,146 & $* * *$ & par_11 \\
\hline ESTEEM & $<--$ & MOT & ,888 &, 140 & 6,365 & $* * *$ & par_12 \\
\hline KUANT & $<--$ & KIN & 1,000 & & & & \\
\hline QUAL & $<--$ & KIN & ,606 & ,088 & 6,886 & $* * *$ & par_13 \\
\hline KNOW & $<--$ & KIN & ,199 & ,076 & 2,605 & ,009 & par_14 \\
\hline
\end{tabular}


Diapari Sosagaon Putra Pane

\begin{tabular}{|c|c|c|c|c|c|c|}
\hline & & Estimate & S.E. & C.R. & $P$ & Label \\
\hline KREAT & <--- $\quad$ KIN & ,107 & ,070 & 1,528 & ,026 & par_15 \\
\hline AKT & $<---\quad$ MOT & ,964 & , 162 & 5,956 & $* * *$ & par_20 \\
\hline
\end{tabular}

Sumber: hasil analisia program AMOS

Berdasarkan pada tabel di atas diatas indikator di atas dari masing-masing variabel memiliki nilai probabilitas yang kurang dari 0,05 . Tanda $(* * *)$ adalah tanda probabilitas yang kurang dari 0,001. Hal ini menyatakan bahwa indikator pada variabel yang diteliti bersifat valid.

3) Analisis Reliabilitas

Tabel 2.

Raliabilitas masing-masing variabel penelitian

\begin{tabular}{|c|c|c|c|c|c|}
\hline Indikator & Tanda & Indikator & $\begin{array}{l}\text { Regreg } \\
\text { weight }\end{array}$ & Kesalahan & CR \\
\hline MISI & $<---$ & BUD & 0,469 & 0,531 & 0,61025 \\
\hline $\mathrm{KON}$ & $<---$ & BUD & 0,887 & 0,113 & \\
\hline ADAP & $<---$ & BUD & 0,024 & 0,976 & \\
\hline \multirow[t]{2}{*}{ PELIB } & $<---$ & BUD & 1,061 & $-0,061$ & \\
\hline & & & 2,441 & 1,559 & \\
\hline KEPRIB & $<---$ & PEM & 1,304 & $-0,304$ & 0,724 \\
\hline TEMP & $<--$ & PEM & 0,6 & 0,4 & \\
\hline KEB & $<---$ & PEM & 0,455 & 0,545 & \\
\hline \multirow[t]{2}{*}{ SIFAT } & $<---$ & PEM & 0,537 & 0,463 & \\
\hline & & & 2,896 & 1,104 & \\
\hline HUB & $<---$ & LING & 1,123 & $-0,123$ & 0,484 \\
\hline KEAM & $<---$ & LING & 0,735 & 0,265 & \\
\hline RUANG & $<---$ & LING & 0,101 & 0,899 & \\
\hline \multirow[t]{2}{*}{ PENER } & $<---$ & LING & $-0,023$ & 1,023 & \\
\hline & & & 1,936 & 2,064 & \\
\hline $\begin{array}{l}\text { FISIOLOGI } \\
\mathrm{S}\end{array}$ & $<---$ & MOT & 0,671 & 0,329 & 0,73954 \\
\hline $\begin{array}{l}\text { KEAMANA } \\
\mathrm{N}\end{array}$ & $<---$ & MOT & 0,967 & 0,033 & \\
\hline SOSIAL & $<---$ & MOT & 1,009 & $-0,009$ & \\
\hline ESTEEM & $<---$ & MOT & 0,662 & 0,338 & \\
\hline $\mathrm{AKT}$ & $<--$ & MOT & 0,615 & 0,691 & \\
\hline & & & 3,924 & 1,382 & \\
\hline KUANT & $\begin{array}{l}<-- \\
\end{array}$ & KIN & 0,876 & 0,124 & 0,6425 \\
\hline QUAL & $<---$ & KIN & 0,56 & 0,44 & \\
\hline
\end{tabular}


Pengaruh Budaya Organisasi, Kepemimpinan, Lingkungan Kerja dan Motivasi Sebagai Variabel Intervening Terhadap Kinerja Dosen

\begin{tabular}{lllrc}
\hline KNOW & $<---$ & KIN & 0,211 & 0,789 \\
\hline KREAT & $<---$ & KIN & 0,123 & 0,877 \\
\hline & & & 1,77 & 2,23 \\
\hline
\end{tabular}

Sumber: data dianalisis

Berdasarkan pada tabel di atas nilai CR diantara 0,6 dan 0,7 bahkan ada yang di atas 0,7 . Hal ini menunjukkan variabel yang dianalisis bersifat reliabel.

\section{4) Uji Normalitas Data}

Uji normalitas data menguji apakah data terdistribusi secara normal. Uji ini menggunakan nilai CR pada skewness diharapkan sekitar kurang lebih 2,58. Bila ada nilai di luar angka tersebut bisa ditoleran apabila nila multivariatenya masih di sekitar kurang lebih 2,58.

Tabel 3.

Nilai normalitas dengan analisis CR (critical ratio)

\begin{tabular}{lrrrrrr}
\hline Variable & Min & Max & Skew & C.R. & Kurtosis & C.R. \\
\hline AKT & 7,000 & 18,000 &, 416 & 1,688 &,- 742 & $-1,507$ \\
\hline KREAT & 7,000 & 15,000 &, 049 &, 198 & $-1,128$ & $-2,291$ \\
\hline KNOW & 12,000 & 22,000 &, 193 &, 785 &,- 973 & $-1,977$ \\
\hline QUAL & 10,000 & 23,000 &, 172 &, 698 &,- 519 & $-1,054$ \\
\hline KUANT & 6,000 & 20,000 &, 588 & 2,387 &, 937 & 1,904 \\
\hline ESTEEM & 4,000 & 16,000 &, 146 &, 591 &, 496 & 1,007 \\
\hline SOSIAL & 4,000 & 15,000 &, 474 & 1,925 & 1,438 & 2,921 \\
\hline KEAMANAN & 4,000 & 15,000 &, 398 & 1,616 & 1,220 & 2,479 \\
\hline FISIOLOGIS & 9,000 & 19,000 & $-1,089$ & $-4,424$ &, 349 &, 709 \\
\hline PENER & 6,000 & 13,000 &,- 071 &,- 288 & $-1,386$ & $-2,816$ \\
\hline RUANG & 7,000 & 13,000 &, 014 &, 057 & $-1,628$ & $-3,306$ \\
\hline KEAM & 6,000 & 13,000 &, 352 & 1,431 &,- 044 &,- 089 \\
\hline HUB & 5,000 & 13,000 &,- 050 &,- 203 &, 152 &, 309 \\
\hline SIFAT & 5,000 & 14,000 &,- 493 & $-2,002$ &,- 856 & $-1,738$ \\
\hline KEB & 5,000 & 14,000 &,- 268 & $-1,088$ &,- 253 &,- 515 \\
\hline TEMP & 5,000 & 13,000 &,- 624 & $-2,534$ & $-1,039$ & $-2,110$ \\
\hline KEPRIB & 24,000 & 51,000 &,- 529 & $-2,148$ &,- 672 & $-1,364$ \\
\hline PELIB & 4,000 & 15,000 &, 231 &, 939 & 1,071 & 2,175 \\
\hline ADAP & 4,000 & 15,000 &, 377 & 1,531 & 1,000 & 2,031 \\
\hline KON & 4,000 & 15,000 &, 348 & 1,415 &, 574 & 1,166 \\
\hline MISI & 4,000 & 15,000 &, 296 & 1,202 &, 872 & 1,771 \\
\hline Multivariate & & & & & 122,204 & 19,561 \\
\hline Sumb: & & & & & &
\end{tabular}

Sumber: data dianalisis 
Berdasarkan pada data di atas nilai CR mendekati nilai 2,58 meskipun ada beberapa nilai CR yang jauh di atas atau di bawah 2,58.

\section{5) Menilai Goodness of Fit Indeks}

Penilaian terhadap model dilakukan dengan uji Godness of Fit Indeks. Hasil analisis terhadap model ini dapat dilihat pada hasil analisis tersebut.

Tabel 4.

Hasil RMSEA

\begin{tabular}{lrrrr}
\hline Model & RMSEA & LO 90 & HI 90 & PCLOSE \\
\hline Default model &, 300 &, 287 &, 312 &, 000 \\
\hline Independence model &, 390 &, 378 &, 401 &, 000 \\
\hline Sumbr: data dianalisis & & & &
\end{tabular}

Nilai RMSEA $<0,08$. Nilai RMSEA tidak memenuhi persyaratan atau dikatakan marginal.

Pengujian lain adalah dengan melihat nilai GFI. Nilai GFI adaah 0,459. Nilai ini lebih besar dari 0,90. Berdasarkan pada hal tersebut dapat dikatakan bahwa model bersifat Fit atau baik.

Nilai Merupakan pengembangan dari GFI yang disesuaikan dengan ratio degree of freedom untuk proposed model dengan degree of freedom untuk null model. Nilai yang direkomendasikan adalah $\geq 0,90$. Nilai GFI 0,459 .

Tabel 5.

Nilai GFI

\begin{tabular}{lrrrr}
\hline Model & RMR & GFI & AGFI & PGFI \\
\hline Default model & 1,793 &, 459 &, 313 &, 361 \\
\hline Saturated model &, 000 & 1,000 & & \\
\hline Independence model & 2,523 &, 280 &, 208 &, 254 \\
\hline
\end{tabular}

Sumber: data dianalisis

Parsimonious normal fit index merupakan modifikasi dari NFI. PNFI memasukan jumlah degree of freedom yang digunakan untuk mencapai level fit. Semakin tinggi PNFI semakin baik. Kegunaan utama dari PNFI adalah untuk membandingkan model dengan degree of freedom yang berbeda. Digunakan untuk membandingkan model alternatif sehingga tidak ada nilai yang direkomendasikan sebagai nilai fit yang diterima. Namum demikian jika membandingkan dua model maka perbedaan PNFI 0.60 sampai 0.90 menunjukan adanya perbedaan model yang signifikan. 
Pengaruh Budaya Organisasi, Kepemimpinan, Lingkungan Kerja dan Motivasi Sebagai Variabel Intervening Terhadap Kinerja Dosen

Tabel 6.

Nilai NFI

\begin{tabular}{lrrrrr}
\hline \multirow{2}{*}{ Model } & $\begin{array}{r}\text { NFI } \\
\text { Delta1 }\end{array}$ & $\begin{array}{r}\text { RFI } \\
\text { rho1 }\end{array}$ & $\begin{array}{r}\text { IFI } \\
\text { Delta2 }\end{array}$ & $\begin{array}{r}\text { TLI } \\
\text { rho2 }\end{array}$ & CFI \\
\hline Default model &, 465 &, 383 &, 492 &, 409 &, 488 \\
Saturated model & 1,000 & & 1,000 & & 1,000 \\
Independence model &, 000 &, 000 &, 000 &, 000 &, 000 \\
\hline
\end{tabular}

Sumber: data dianalisis

Tucker-Lewis Index (TLI) atau dikenal dengan nonnormed fit index (NNFI) pertama kali diusulkan sebagai alat untuk mengevaluasi analisis faktor, tetapi sekarang dikembangkan oleh SEM. Ukuran ini menggabungkan ukuran parsimony. Nilai TLI 0,409 jadi termasuk fit. Kedalam indek komparasi antara proposed model dengan null model dan nilai TLI berkisar dari 0 sampai 1.0. nilai TLI yang direkomendasikan adalah $\geq 0.90$.

\section{B. Pembahasan.}

Pada hipotesis yang pertama dapat dibuktikan bahwa Budaya organisasi berpengaruh terhadap motivasi Dosen pada kampus politeknik di Kota Bekasi secara parsial. Hal ini sesuai dengan penelitian yang dilakukan oleh (Feldman \& Weitz, 1988); perilaku individu berkenaan dengan tindakan yang nyata dilakukan oleh seseorang dapat diartikan bahwa dalam melakukan tindakan seseorang pasti akan tidak terlepas dari perilakunya. Budaya tersebut akan berdampak pada tinggi rendahnya motivasi.

Pada hipotesis yang kedua Kepemimpinan berpengaruh terhadap Motivasi Dosen pada kampus Politeknik di kota Bekasi secara parsial. Berdasarkan analisis estimasi bernilai negatif yang berarti semakin tinggi Kepemimpinan akan berdampak pada menurunya Motivasi dosen dalam bekerja. Hal ini perlu diwaspadai seperti pada penerapan kepemimpinan yang terlalu kaku justru berdampak pada penurunan Motivasi dosen. Hal ini juga sesuai dengan penelitian yang dilakukan (Zehir, Ertosun, Zehir, \& Müceldilli, 2012) yaitu kepemimpinan. Judul penelitian ini adalah The effect of leadership and supervisory commitment to organizational performance. Pada penelitian tersebut disebutkan bahwa variabel kepemimpinan berpengaruh secara signifikan terhadap motivasi dosen yang bekerja pada perusahaan. 
Pada hipotesis yang ketiga Lingkungan Kerja berpengaruh terhadap Motivasi Dosen pada kampus Politeknik di Kota Bekasi secara parsial. Nilai estimasi positif artinya semakin baik kondisi Lingkungan Kerja maka motivasi dosen juga semakin besar. Hal ini sesuai dengan penelitian (Raziq \& Maulabakhsh, 2015). Penelitian ini berjudul Impact of working envionment on job satisfaction. Penelitian ini dilakukan pada sejumlah karyawan pada institusi pendidikan, sektor perbankan dan industri telekomunikasi yang beroperasi di Pakistan.

Pada hipotesis yang keempat Motivasi berpengaruh terhadap Kinerja Dosen pada kampus Politeknik di Kota Bekasi secara parsial. Nilai estimasi positif berarti semakin tinggi motivasi maka kinerja dosen juga semakin baik. Hal ini sesuai dengan penelitian yang dilakukan sebelumnya. Penelitian tersebut diakukan oleh Mahardika et all (2012) yang berjudul Pengaruh motivasi terhadap kinerja karyawan (survey karyawan PT. Axa Financial Indonesia sales office Malang menyatakan bahwa motivasi berpengaruh terhadap kinerja karyawan. Penelitian ini dilakukan pada karyawan perusahaan PT. Axa Financial Indonesia sales office Malang.

Pada hipotesis kelima Budaya Organisasi berpengaruh terhadap Kinerja Dosen pada kampus di Kota Bekasi Indonesia. Hasil penelitian ini berbeda dengan penelitian sebelumnya. Budaya organisasi perlu diperhatikan sebagai variabel yang berdampak pada kinerja meskipun pada penelitian ini tidak berpengaruh.

Pada hipotesis ke enam Kepemimpinan berpengaruh terhadap Kinerja Dosen pada kampus Politeknik di Kota Bekasi. Nilai CR 4,225 lebih besar dari 1,96 dan nilai p adalah sangat signifikan. Nilai estimasi adalah 0,033. Nilai estimasi tersebut positif yang berarti semakin baik kepemimpinan maka kinerja dosen juga akan semakin besar.

Pada hipotesis ke tujuh Lingkungan Kerja berpengaruh terhadap Kinerja Dosen pada kampus Politeknik di Kota Bekasi. Nilai CR 1,974 lebih besar dari 1,96 dan nilai p adalah 0,048 lebih kecil dari 0,05. Nilai estimasi adalah 0,094. Hal ini sesuai dengan hasil penelitian sebelumnya yang dilakukan oleh (Jonison, Samsir, \& Marzolina, 2014).

Judul penelitiannya adalah pengaruh kepemimpinan terhadap kinerja melalui motivasi pada Bank Artha Graha Pekanbaru. Hasil penelitian menunjukkan bahwa motivasi memperbesar pengaruh kepemimpinan terhadap kinerja karyawan pada perusahaan. 
Pada hipotesis kedelapan Budaya organisasi berpengaruh terhadap Kinerja Dosen pada kampus di Kota Bekasi Indonesia melalui motivasi. Pengaruh langsung sebesar -,346 dan pengaruh tidak langsung -,274. Pengaruh tidak langsung lebih kecil dibanding dengan pengaruh langsung maka motivasi bukan variabel intervening. Dalam analisis ini nilai yang dianalisis dinyatakan bentuk nilai mutlak atau tanpa nilai minus. Hal ini tidak sesuai dengan penelitian sebelumnya seperti peneliti (Yusniar, 2017). Judul penelitian ini adalah pengaruh budaya organisasi terhadap kinerja karyawan melalui motivasi di SETDA Kabupaten Aceh Utara. Hasil penelitian menunjukkan bahwa motivasi dapat memidiasi hubungan antara budaya organisasi dengan kinerja organisasi.

Pada hipotesis kesembilan Kepemimpinan berpengaruh terhadap Kinerja Dosen pada kampus di Kota Bekasi Indonesia melalui motivasi. Nilai pengaruh langsung 0,022 sedangkan nilai pengaruh tidak langsung sebesar -0,011. Pengaruh tidak langsung lebih kecil dibanding dengan pengaruh langsung maka motivasi bukan variabel intervening. Hal ini belum sesuai dengan penelitian sebelumnya seperti pada penelitian (Jonison et al., 2014). Judul penelitiannya adalah pengaruh kepemimpinan terhadap kinerja melalui motivasi pada Bank Artha Graha Pekanbaru. Hasil penelitian menunjukkan bahwa motivasi memperbesar pengaruh kepemimpinan terhadap kinerja karyawan pada perusahaan.

Pada hipotesis ke sepuluh Lingkungan Kerja berpengaruh terhadap Kinerja Dosen pada kampus Politeknik di Kota Bekasi melalui motivasi. Nilai pengaruh langsung 1,101 sedangkan nilai pengaruh tidak langsung sebesar 1,007. Pengaruh tidak langsung lebih kecil dibanding dengan pengaruh langsung maka motivasi bukan variabel intervening.Namun hasil penelitian ini belum sesuai dengan penelitian sebelumnya.

\section{Kesimpulan}

Budaya Organisasi berpengaruh terhadap motivasi Dosen pada kampus Politeknik di Kota Bekasi secara parsial. Nilai CR pengaruh budaya organisasi terhadap motivasi adalah $-2,337$ dan nilai $\mathrm{p}$ adalah 0,019 . Nilai CR lebih besar dari 1,96 dan nilai 
p lebih kecil dari 0,05. Hal ini berarti budaya organisasi berpengaruh terhadap motivasi dosen pada kampus Politeknik di Kota Bekasi. Besarnya motivasi adalah -0,185.

Kepemimpinan berpengaruh terhadap motivasi Dosen pada kampus Politeknik di Kota Bekasi secara parsial. Nilai CR pengaruh budaya organisasi terhadap motivasi adalah -2,337 dan nilai p adalah 0,019. Nilai CR lebih besar dari 1,96 dan nilai p lebih kecil dari 0,05 . Hal ini berarti budaya organisasi berpengaruh terhadap motivasi dosen pada kampus Politeknik di Kota Bekasi. Besarnya motivasi adalah -0,185.

Lingkungan Kerja berpengaruh terhadap motivasi Dosen pada kampus Politeknik di kota Bekasi secara parsial. Nilai CR 1,94 dan nilai p 0,048. Nilai CR lebih besar dari 1,96 dan nilai p lebih kecil dari 0,05. Nilai estimasi adalah 0,094.

Motivasi berpengaruh terhadap Kinerja Dosen pada kampus Politeknik di Kota Bekasi secara parsial. Nilai CR 8,308 lebih besar dari 1,96 dan nilai p adalah sangat signifikan. Nilai estimasi adalah 1,481.

Budaya Organisasi berpengaruh terhadap Kinerja Dosen pada kampus di Kota Bekasi Indonesia. Nilai CR -0,924 lebih kecil dari 1,96 dan nilai $\mathrm{p}$ adalah 0,356 dan tidak signifikan. Nilai estimasi adalah -0,072.

Kepemimpinan berpengaruh terhadap Kinerja Dosen pada kampus Politeknik di Kota Bekasi. Nilai CR 4,225 lebih besar dari 1,96 dan nilai p adalah sangat signifikan. Nilai estimasi adalah 0,033 .

Lingkungan Kerja berpengaruh terhadap Kinerja Dosen pada kampus Politeknik di Kota Bekasi. Nilai CR 1,974 lebih besar dari 1,96 dan nilai p adalah 0,048 lebih kecil dari 0,05. Nilai estimasi adalah 0,094.

Budaya Organisasi berpengaruh terhadap Kinerja Dosen pada kampus di Kota Bekasi Indonesia melalui motivasi. Pengaruh langsung sebesar -,346 dan pengaruh tidak langsung -,274. Pengaruh tidak langsung lebih kecil dibanding dengan pengaruh langsung maka motivasi bukan variabel intervening. Dalam analisis ini nilai yang dianalisis dinyatakan bentuk nilai mutlak atau tanpa nilai minus.

Kepemimpinan berpengaruh terhadap Kinerja Dosen pada kampus di Kota Bekasi Indonesia melalui motivasi. Nilai pengaruh langsung 0,022 sedangkan nilai pengaruh tidak langsung sebesar -0,011. Pengaruh tidak langsung lebih kecil dibanding dengan pengaruh langsung maka motivasi bukan variabel intervening. Dalam analisis ini nilai yang dianalisis dinyatakan bentuk nilai mutlak atau tanpa nilai minus. 
Pengaruh Budaya Organisasi, Kepemimpinan, Lingkungan Kerja dan Motivasi Sebagai Variabel Intervening Terhadap Kinerja Dosen

Lingkungan Kerja berpengaruh terhadap Kinerja Dosen pada kampus Politeknik di Kota Bekasi melalui motivasi. Nilai pengaruh langsung 1,101 sedangkan nilai pengaruh tidak langsung sebesar 1,007. Pengaruh tidak langsung lebih kecil dibanding dengan pengaruh langsung maka motivasi bukan variabel intervening. Dalam analisis ini nilai yang dianalisis dinyatakan bentuk nilai mutlak atau tanpa nilai minus 
Diapari Sosagaon Putra Pane

\section{BLIBIOGRAFI}

Feldman, D. C., \& Weitz, B. A. (1988). Career plateaus reconsidered. Journal of Management, 14(1), 69-80.

Jonison, J., Samsir, S., \& Marzolina, M. (2014). Pengaruh Kepemimpinan terhadap Kinerja melalui Motivasi Instrinsik pada Bank Artha Graha Pekanbaru. Jurnal Online Mahasiswa Fakultas Ekonomi Universitas Riau, 1(2).

Priyono, M. (2016). Metode penelitian kuantitatif.

Rahmayanti, D., \& Afandi, I. (2014). Analisis Pengaruh Kepemimpinan, Motivasi, Lingkungan Kerja, dan Kedisplinan Terhadap Kinerja Karyawan (Studi Kasus: Operator Welding 1A, PT. XYZ Motor). Jurnal Optimasi Sistem Industri, 13(1), $556-561$.

Raziq, A., \& Maulabakhsh, R. (2015). Impact of working environment on job satisfaction. Procedia Economics and Finance, 23, 717-725.

Saridawati. (2018). PENGELOLAAN DAN PENGEMBANGAN SUMBER DAYA MANUSIA PADA PT. ATMONI SHAMASTA PREZKI. Syntax Literate; Jurnal Ilmiah Indonesia, 3, No.9 Se, 107.

Suddin, A. (2010). Pengaruh Kepemimpinan, Motivasi, dan Lingkungan Kerja Terhadap Kinerja Karyawan (Studi Pada Kantor Kecamatan Laweyan Kota Surakarta). Jurnal Manajemen Sumber Daya Manusia, 4(2).

Sugiyono, M. P. (2016). Pengembangan Research and Development. Bandung: Alvabeta.

Yusniar, Y. (2017). Pengaruh Budaya Organisasi Terhadap Kinerja Melalui Motivasi di Sekretariat Daerah Kabupaten Aceh Utara. E-Mabis: Jurnal Ekonomi Manajemen Dan Bisnis, 17(1), 85-104.

Zehir, C., Ertosun, Ö. G., Zehir, S., \& Müceldilli, B. (2012). Total quality management practices' effects on quality performance and innovative performance. ProcediaSocial and Behavioral Sciences, 41, 273-280. 